\title{
Development of the Ergonomic Activity Sampling (EAS) Method to Analyse Video-Documented Work Processes with Activity Sampling
}

\author{
Landau Kurt L*, Nadeau Sylvie and LeFloch Tiphaine \\ Department of Mechanical Engineering, École de technologie supérieure, Montréal, \\ Canada
}

*Corresponding author: Kurt Landau, Department of Mechanical Engineering, École de

Research Article

Volume 2 Issue 4

Received Date: July 13, 2018

Published Date: July 26, 2018

DOI: $10.23880 /$ eoij- 16000167 technologie supérieure, Montréal, Canada, Tel: +43/676 92822 78; Email: office@ioa-online.at

\section{Abstract}

Ergonomics analyses examine design parameters of work processes, e.g. postures and movements or action forces, with the aim of assessing work systems or work processes with regard to feasibility and long-term tolerability. Numerous applications of ergonomics analysis at "normal" industrial and service workplaces can be found in the relevant literature as well as in practical field studies. In contrast, there are only a few methodical presentations of ergonomics analysis under critical working and environmental conditions, e.g. in fire brigade and medical emergency operations, in heat and cold environments, in radioactive contamination of workplaces, etc. With the EAS, a procedure for video-supported activity sampling analysis is presented. Based on case studies from aircraft de-icing, it is shown that video-based activity sampling studies allow a well-founded analysis of postures and movements with a cost-benefit ratio that is acceptable to the analyst.

Keywords: Ergonomics Analysis; Work Analysis; Activity Sampling; Video-Based Analysis; De-Icing of Aircraft

\section{Introduction}

Since the times of Frank and Lillian Gilbreth, the analysis of the design status of a work system and the ergonomic evaluation of work processes have moved not only the relevant technical disciplines, but above all also the practitioners of industrial engineering in the companies. In order to not only endure the conflicting objectives between humanity and economy, but also to find a solution acceptable to both business parties, precise knowledge of working postures and movements, the required action forces, the repetitiveness of working actions and the time requirements of individual tasks is required. of course, the increasingly significant psychological stress and physico-chemical environmental influences are then added - but this is not the subject of this paper.

Work analyses [1,2] are performed, since questions of efficiency and effectiveness of work and possible optimisations have been an issue for superiors for many centuries [3]. But these were often primitive approaches based on the method of looking closely. In principle, there have been two quite contradictory approaches in the past: the questioning of superiors or the job holder themselves, or time measurement. The survey on the physical stress experienced or classified by the supervisor can show large deficits with regard to validity, objectivity and test- 


\section{Ergonomics International Journal}

retest reliability. The time measurement of individual tasks can only be assigned to typical postures and movements afterwards. The next step would then be to derive requirements for the musculoskeletal system - but this was often omitted. In fact, no evaluations of these two approaches to validity, objectivity, reliability etc. were known until the second half of the 20th century. Questionnaires or forms regarding the work situation are usually nominal or ordinally scaled and therefore show weaknesses with regard to the precise derivation of design measures. Time measurements of working processes are on a metric scale level, and therefore allow valid statements regarding the workload duration, but are complex and not very productive with regard to the workload magnitude. With the development of systems of predetermined motion times (PMTS), e.g. MTM, MOST or Work factor, instruments have been available since the end of the Second World War which allowed profound statements on the "atomic" level of work processes - the PMTS alone were even more complex than stopwatch measurements. The interpretation of their results was also primarily aimed at productivity, not humanity. Only in the last two decades, at least for MTM, a determined focus on ergonomic design and support in solving the conflict of objectives between economy and humanity is noticed [4]. If the metaphor "quantum leap" is to be used, the development of the Ergonomic Assessment Worksheet (EAWS) [5] and its integration into the MTM process under the caption "Human Work Design" [6] is an innovation. However, this approach is even more complex than time study and, under cost-benefit considerations, can only be justified ex-ante in the planning stage of new work systems and only with computer support.

This raises the question of an ergonomically valid procedure for analysing the current state of work systems and work processes, using the current wealth of knowledge and experience but acceptable from a procedural point of view. Once an application economic ergonomics analysis has been developed, it would be the screening procedure of the first stage in a two-stage model. In the second, more detailed step, for example, the EAWS could then be used as an elaborate, detailed procedure.

\section{Current State of Research}

\section{Ergonomics Analysis and Analysis Effort}

This section examines the current state of research exclusively with regard to procedurally acceptable ergonomics analyses for actual states of work systems or work processes. In this paper we continue to limit ourselves solely to the analysis of musculo-skeletal requirements.
To this end, the following questions must first be clarified:

1. What are "ergonomics analyses"?

2. What is "procedurally acceptable"?

1) Ergonomic analyses examine design parameters of work processes, e.g. postures and movements or action forces, with the aim of assessing work systems or work processes with regard to feasibility and long-term tolerability. The concept of ergonomics analysis is therefore much narrower than that of work analysis already mentioned above. There are numerous synopses (examples: [7-9]) on the methods and results of ergonomics analysis, so that a further overview is unnecessary here.

2) Industrial practitioners could expect a statement - at least at the level of a traffic light display (DIN ISO/TR 14121 [10]) - on the current design state after a site inspection, some kind of actual recording, a subsequent evaluation and ergonomic evaluation with a lower analyst effort, for example, smaller than a multiple of the time per unit te (unit time) still to be determined [11].

This means that data must be collected until an almost representative picture of the existing musculo-skeletal requirements has been achieved. For the operationalisation of the word "representative", for example, a system of physical requirements can be used (on "arbeitswissenschaftlichen Repräsentativität: [12]). An activity sample representative of physical work must ensure that the entire spectrum of

- Static posture work;

- Static strenuous work;

- Heavy dynamic muscle work;

- One-sided dynamic muscle work and;

- Sensor motor work.

- If available in individual cases - can be mapped and analysed.

\section{Ergonomic Assessment Worksheet (EAWS)}

The Ergonomic Assessment Worksheet (EAWS; [5,1315]) is a tool for the holistic evaluation of physical workloads. It is implemented in digital human models like JACK [16] and serves as an ergonomic evaluation tool within EMA (IMK-EMA [17]) and MTM ergonomics [18]. EAWS and all references mentioned here are assumed to be known.

The application of MTM - and thus also of EAWS in MTM ergonomics - is time-consuming. For a one minute execution time e.g. with MTM-UAS 15-30 minutes analysis time (plus EAWS-coding time) are required [12]. For a situation analysis of an existing work system, this effort is 


\section{Ergonomics International Journal}

often unacceptable - in contrast to computer-supported planning analyses for work systems that do not yet exist.

This raises the question of a procedure based on the EAWS items and the EAWS system for the rapid analysis of an existing work system. MTM has presented some approaches (DMTM [19]). However, the reference to video-supported analyses of a current state is missing here. In line with this deficit, an attempt is being made to take account of the development of the EAS.

\section{Activity Sampling Method}

In the activity sampling procedure, the frequency of occurrence of tasks or their ergonomic properties are determined with the aid of random short-term observations. This can be done directly at the workplace or via video analysis. Large sample sizes provide a realistic picture of the actual situation. Activity sampling has been known for almost a hundred years and is quite often used to improve the organisation of work and operations. Haller-Wedel has described the method and application in details [20]. Some applications of the activity sampling in ergonomics are described in the literature $[8,21,22]$.

The following conditions must be met when conducting an activity sampling [4]:

- Representativeness: "typical" conditions exist in the period covered;

- Randomness: every point in time in the collection period and thus every occurrence is included in the survey with equal probability;

- Sample size: A sufficiently large number is observed for the performance or property of interest in order to accurately estimate the true proportional values.

The statistical determination equations of the activity sampling (absolute and relative confidence interval, number of observations required, etc.) are described in detail in Haller-Wedel, so that they need not be repeated here [20].

\section{Ovako Working Posture Assessment System (OWAS) Procedure}

The OWAS method $[23,24]$ has the longest tradition in the combination of posture analysis and activity sampling. An analyst classifies each observation:

- Head position (5 variants);

- Weight or power requirements (3 variants);

- Leg position (7 variants);

- Arm position (3 variants);

- back posture (4 variants);
In addition to the head positions, 84 OWAS basic positions are possible, which the analyst can use as a computer or paper-based classification aid [25]. After determining the frequency of position combinations, classes of measures and emergency instructions for the redesign of workplaces are derived. There are numerous applications of the OWAS method, therefore only a few occupational studies are mentioned here as examples: position analyses in nursing activities, for car mechanics, for carpentry work or for construction [26-29].

A serious disadvantage of the OWAS process is that it is neither integrated as a "stand-alone process" into a comprehensive workload/strain analysis and system [30] nor can technical-ergonomic or organizational design recommendations be derived.

\section{Other Activity Sampling Methods in Ergonomics}

Kee and Karwowski [31] compared three observation methods for posture analysis, OWAS, RULA and REBA, and came to the conclusion that all three methods underestimate the workload of static posture work. Walker, et al. [32] has an analytical approach that makes use of activity sampling. Among other methods, Hierarchical Task Analysis (HTA) is provided. However, a discussion of physical stress factors in the sense of this article is missing.

The article by Buchholz, et al. [33] deals with nonrepetitive work, especially in the construction industry. The article by Janowitz, et al. [8] deals with work in hospitals.

\section{Video-Supported Ergonomics Analysis}

Up to now, the main focus of video-supported ergonomics analysis has been on movement analysis in sports and rehabilitation. Individual studies deal with the simulation-based validation of ergonomics with the help of digitally described human movements [34]. Software manufacturers for work and time studies now also offer video-based analyses (DMC-ORTIM [35]).

\section{Working Hypotheses in the Development of the EAS}

From the methodological deficits of other procedural approaches described in Section 2, the following working hypotheses can be derived, which should form the basis for the development of an ergonomic survey procedure based on activity sampling:

\section{Content}

- The procedure should be classified in a workload/strain system; 


\section{Ergonomics International Journal}

- It should be possible to derive design deficits or design requirements of workplaces from the process results;

- The procedure is intended to capture all essential 2D and 3D body postures;

- The procedure should be compatible with the EAWS survey method and results;

- It should be possible to derive a cadastre with the physical requirements of the examined work centre collective from the procedure.

\section{Formal}

1. The procedure must meet the usual test statistical criteria of validity, objectivity, etc. [36];

2. The application economy must be satisfactory; in particular, the process effort must be significantly lower than the application of the EAWS;

3. The procedure should be designed as activity sampling and must at least partially meet the conditions of activity sampling (see above);
4. The procedure must above all be accessible to videosupported classification.

\section{Methodology}

EAS contains 27 items to analyse

- Body postures and body movements;

- Static and dynamic action forces;

- Manual materials handling.

Body postures may be analysed in a 3-dimensional way in order to consider trunk rotation, lateral bending and far reach positions. Loads and action forces $\mathrm{F}<30-40$ $\mathrm{N}$ are included when analysing postures. Only exceeding loads and forces should be separately analysed in sections $B$ and $C$.

The EAS-structure - derived from EAWS-structure - is as follows (Table 1):

\begin{tabular}{|c|c|c|}
\hline \multicolumn{2}{|l|}{ A) Postures } & Item \\
\hline \multirow{8}{*}{ Standing } & 1 & upright standing with suitable support \\
\hline & 2 & standing or walking, no body support \\
\hline & 3 & bent forward $\left(20^{\circ}-60^{\circ}\right)$, no support \\
\hline & 4 & bent forward $\left(20^{\circ}-60^{\circ}\right)$, with suitable support \\
\hline & 5 & strongly bent forward $>60^{\circ}$, no support \\
\hline & 6 & strongly bent forward $>60^{\circ}$, with suitable support \\
\hline & 7 & upright arms at/above shoulder level \\
\hline & 8 & upright arms above head level \\
\hline \multirow{5}{*}{ Sitting } & 9 & $\begin{array}{l}\text { upright with back support } \\
\text { slightly bent forward or } \\
\text { slightly bent backward }\end{array}$ \\
\hline & 10 & upright no back support \\
\hline & 11 & bent forward \\
\hline & 12 & upright arms at/above shoulder level \\
\hline & 13 & upright, arms above head level \\
\hline \multirow{3}{*}{ Kneeling or crouching } & 14 & upright \\
\hline & 15 & bent forward \\
\hline & 16 & arms at/above shoulder level \\
\hline \multirow{2}{*}{ Lying \& climbing } & 17 & lying on back, breast or side, arms above head \\
\hline & 18 & climbing \\
\hline \multirow{2}{*}{ B) Action forces } & 19 & load onto fingers (e.g. clips, plugs) \\
\hline & 20 & action forces required (loads $\rightarrow$ see below) \\
\hline \multirow{2}{*}{$\begin{array}{l}\text { C) Manual materials } \\
\text { handling }\end{array}$} & 21 & reposition, carrying and holding (loads $>2 \mathrm{~kg}$ ) \\
\hline & 22 & pushing and pulling (trolleys etc. $>40 \mathrm{~kg}$ ) \\
\hline \multirow{5}{*}{ D) Extras: Whole body } & 23 & working on moving objects \\
\hline & 24 & accessibility (e.g. entering motor or passenger compartment) \\
\hline & 25 & vibration, counter shocks, pulses \\
\hline & 26 & joint position (especially wrist) \\
\hline & 27 & $\begin{array}{c}\text { special load situations } \\
\text { (please describe in detail) }\end{array}$ \\
\hline
\end{tabular}

Table1: EAS-structure and contents (overview). 
Each of the 27 items has an item number, a description, and a relevant pictogram (Figure 1).

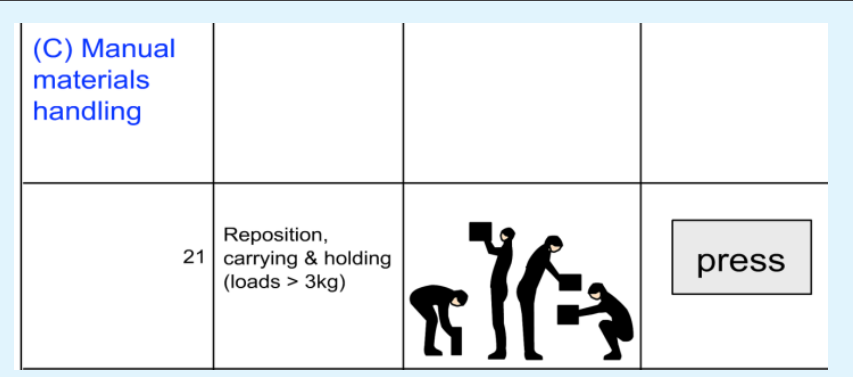

Figure1: Structure of an EAS item (example).

As for working postures, we are distinguishing between 2D and 3D. 2D means that the body of the worker might be mapped in a two-axes-graph. Very often the workers are rotating or laterally bending their trunk or doing a far reach; this has been named as 3D.

EAS is designed for video use with a double screen or a correspondingly large screen, which allows parallel work with Media player and Excel. Details of posture and body movement should be well recognized. The estimation of the force application by video observation alone is naturally difficult, so that for the corresponding EAS items (Table 1 ) only a very rough estimate can be expected.

The following Figure 2 shows sections from the Excel user interfaces.

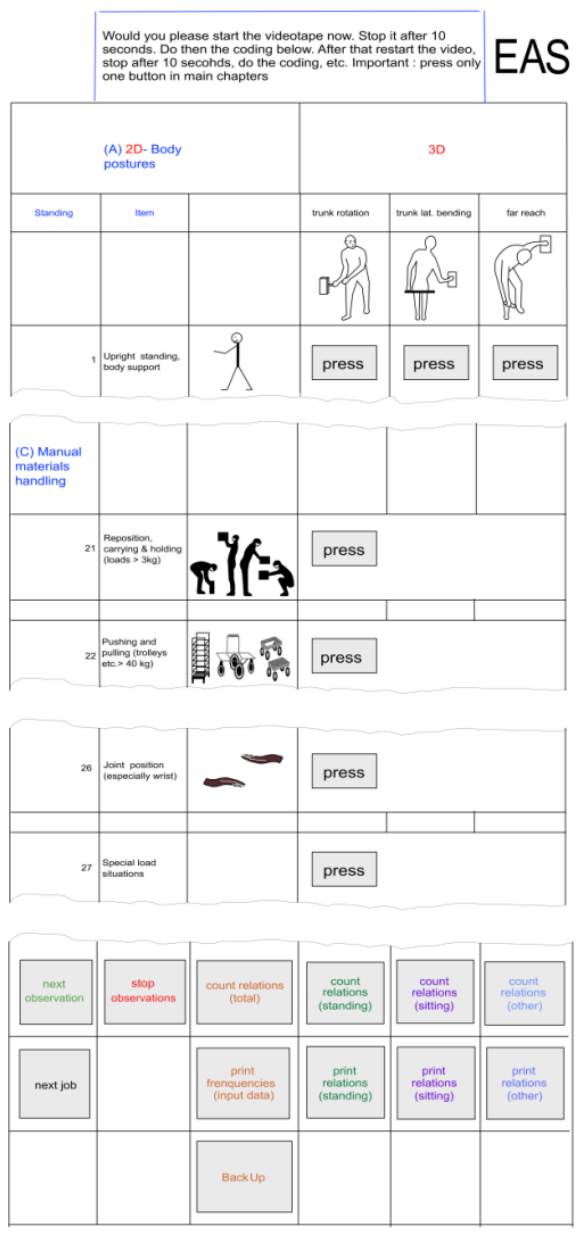

Figure2: Sections of the Excel user interface. 
EAS provides the user with a raw data matrix for all workstations or work processes examined, which can be printed out or processed further if required. Relative frequencies are determined for all items as well as for the subgroups of posture (standing, sitting, other). Statistical tests of the collected data material are performed with the exported data matrix outside of EAS.

A work system cadastre can be generated. For this the classifications are evaluated analogous to the EAWS criteria for each workplace and entered in a level, e.g. from the two summary variables posture and further physical stress factors.

\section{Evaluation of the EAS}

In accordance with the above explanations of ergonomic science representativeness, 10 video studies were selected from workplaces covering the most important physical requirements: static posture work and static strenuous work, heavy and one-sided dynamic muscle work and sensorimotor work. The validity and inter-rater reliability of the EAS was examined using these video films [37].

\section{Application example}

The EAS was used for the first time in a study on centralized aircraft de-icing [37-39], a highly critical and reliable activity held before plane take-off. Ethical approval for this study was given by the Ethical Committee of École de technologie supérieure, in Montreal (Canada), on November 2016. The working system of open-basket aircraft de-icers is described in details in the publications cited. It is a psychophysically very strenuous work in which static posture work, static strenuous work and the entire physical-chemical environmental influences play a major role. Here - as with many other activities - direct on-site analysis is not permitted for safety reasons. Video analysis is therefore imperative.

Figure 3 shows an example of a de-icer's EAS analysis. The classification took place in 10-second intervals.

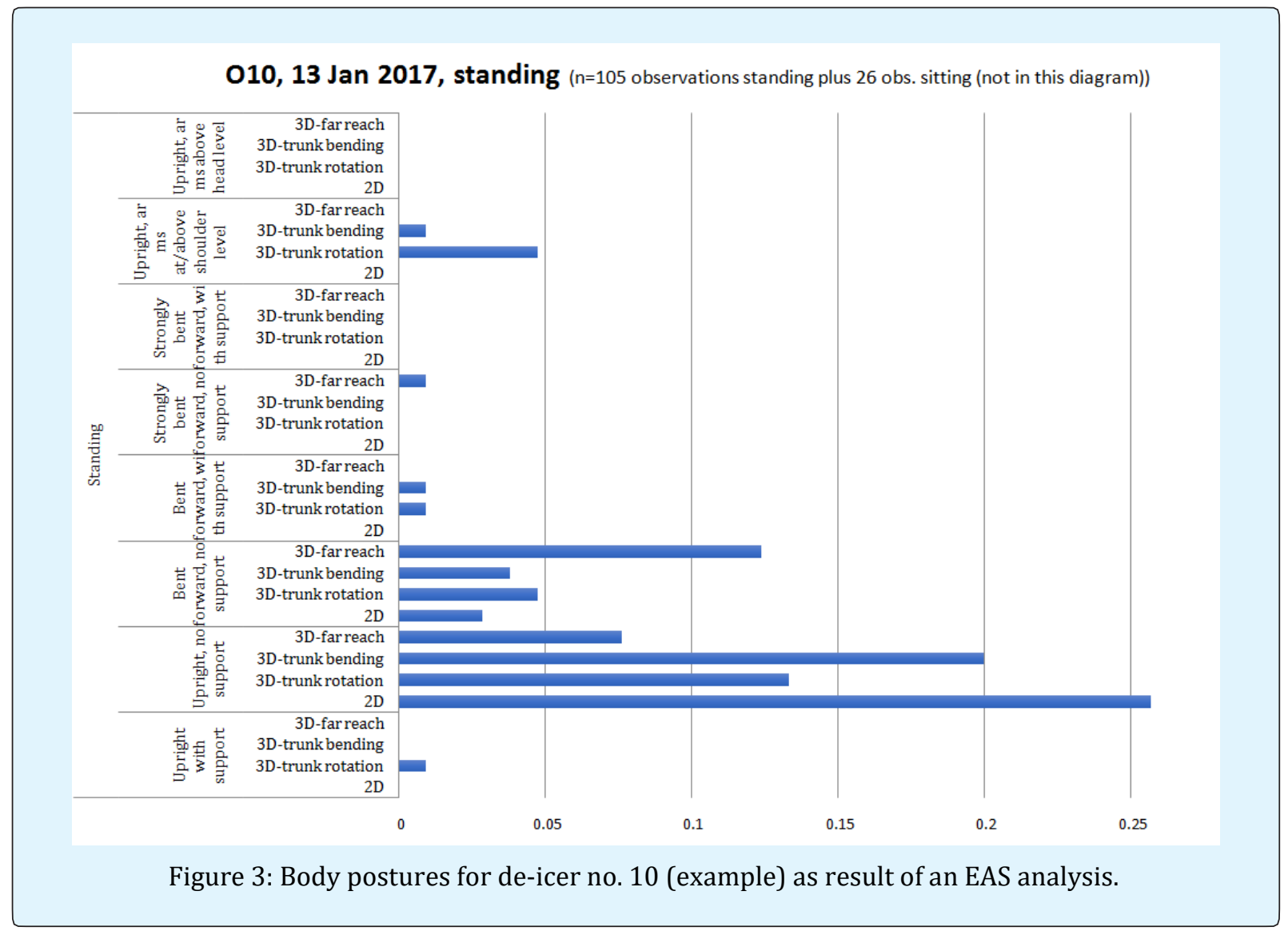

A total of 11 video recordings of complete de-icing shifts were obtained. Each video file contains recordings made with three cameras, two of which were anchored on the basket at right angles to each other, the third located in the control tower and filming the overall scene. 


\section{Ergonomics International Journal}

The video-supported time study reported in this paper is based on an excerpt of between 0.75 and 1.5 hours' duration from the recording of the full shift. We made every endeavor to select only representative excerpts from the recordings, but were unable to do this in some cases because of extreme weather conditions that made video recording impossible, especially during heavy nocturnal snowfall. A total of 11 EAS-studies were performed with 11 human participants during the period from December 2016 to March 2017.

In this case, the analyst needed about 1.5 hours for the coding. The increased EAS coding time compared to the real video runtime of 37 minutes results from multiple views of the three camera images and slow-motion analyses.

\section{Discussion and Outlook}

Ergonomics analyses examine design parameters of work processes, e.g. postures and movements or action forces, with the aim of assessing work systems or work processes with regard to feasibility and long-term tolerability. Numerous applications of ergonomics analysis at "normal" industrial and service workplaces can be found in the relevant literature as well as in practical field studies. In contrast, there are only a few methodical explanations for ergonomics analysis under critical working and environmental conditions, e.g. in fire brigade and medical emergency operations, in heat and cold environments, in radioactive contamination of workplaces, etc. With the EAS, a procedure for videosupported activity sampling analysis is presented. Based on case studies from aircraft de-icing, we have shown that video-based activity sampling studies allows a wellfounded analysis of postures and movements with a costbenefit ratio that is acceptable to the analyst.

\section{Acknowledgment}

The authors would like to thank École de technologie supérieure and the Natural Science and Engineering Research Council of Canada for their funding support as well as the partner deicing company and its workers for their participation.

\section{References}

1. Landau K, Brauchler R, Brauchler W, Landau A, Bokranz R (1990) Job analysis and work design using ergonomics data bases. In: Karwowski W, Genasidy A, Asfour SS (Eds.), Computer Aided Ergonomics. Taylor \& Francis, London.
2. Landau K, Rohmert W, Brauchler R (1998) Task Analysis: Part I - Guidelines for the practitioner. International Journal of Industrial Ergonomics 22(12): 13-35.

3. Landau K (2013) Mehr tun muessen? (Need to do more?) Ergonomia, Stuttgart.

4. Bokranz R, Landau K (2012) Handbuch Industrial Engineering. Schaeffer-Poeschel, Stuttgart.

5. Schaub Kh, Caragnano G, Britzke B, Bruder R (2013) The European Assembly Worksheet. Theoretical Issues in Ergonomics Science 14 (6): 616-639.

6. Finsterbusch T, Wagner T, Mayer M, Kille K, Bruder R, et al. (2014) Human Work Design: Ganzheitliche Arbeitsgestaltung mit MTM. GfA-Tagungs band, Gestaltung der Arbeitswelt der Zukunft hrsg. v. Gesellschaft für Arbeitswissenschaft Dortmund, pp: 324-326.

7. David GC (2005) Ergonomic methods for assessing exposure to risk factors for work-related musculoskeletal disorders. Occ Med 55(3): 190-199.

8. Janowitz IL, Gillen M, Ryan G, Rempel D, Trupin L, et al. (2006) Measuring the physical demands of work in hospital settings: Design and implementation of an ergonomic assessment. Appl Ergonomics 37(5): 641658.

9. Li G, Buckle P (1999) Current techniques for assessing physical exposure to work-related musculoskeletal risks, with emphasis on posturebased methods. Ergonomics 42(5): 674-695.

10. (2013) Safety of machinery - Risk assessment - Part 2: Practical guidance and examples of methods, DIN ISO/TR 14121-2:2013-02; DIN SPEC 33885:2013-02.

11. REFA (2017) REFA International Productivity Management worldwide.

12. Rohmert W, Rutenfranz J (1975) Arbeitswissenschaftliche Beurteilung der Belastung und Beanspruchung an unterschiedlichen industriellen Arbeitsplätzen. Der Bundesminister für Arbeit und Sozialordnung.

13. Schaub KH (2004) Das Automotive Assembly Worksheet (AAWS). In: Landau K (Eds.), Montageprozesse gestalten. Ergonomia, Stuttgart, pp: 91-111. 


\section{Ergonomics International Journal}

14. Schaub Kh, Rademacher H, Caragnano G, Guth A, Bruder R (2008) Ergonomics risk assessments in automotive and electrical industry based on the dual European concept of health and safety at work. Ergonomics is a lifestyle 40th Annual Conference of the Nordic Ergonomics Society (NES) 11-13 August Reykjavík (Iceland).

15. Schaub KH (2009) Integration of new ergonomic evaluation tools into MTM ergonomics. Proceeding 55 ${ }^{\text {th }}$ GfA-congress Dortmund, GfA Press, pp: 245-248.

16. (2018) Human-centered design, simulation and ergonomics.

17. (2018) IMK-EMA.

18. (2018) MTM ergonomics.

19. (2017) DMTM.

20. Haller-Wedel E (1964) Das Multimomentverfahren in Theorie und Praxis. MünchenHanser.

21. Corlett EN, Madeley SJ, Manenica I (1979) Posture targeting: a technique for recording working postures. Ergonomics 22(3): 357-366.

22. Steiner L, Cornelius K, Turin F, Stock D (1998) Work sampling applied to a human factor analysis of mine worker positioning. Proceeding. Human Factors and Ergonomics Society 42nd Annual Meeting, Chicago Illinois, pp: 1103-1107.

23. Karhu O, Kansi P, Kuorinka I (1977) Correcting working postures in industry: A practical method for analysis. Appl Ergonomics 8(4): 199-201.

24. Karhu O, Hoerkoenen R, Sorvali P, Vepsaelaeinen P (1981) Observing working postures in industry: Examples of OWAS application. Appl Ergonomics 12(1): 13-17.

25. Mattila M, Karwowski W, Vilkki M (1993) Analysis of working postures in hammering tasks on building construction sites using the computerised OWAS method. Appl Ergonomics 14(6): 405-412.

26. Engels JA, Landeweerd JA, Kant Y (1994) An OWASbased analysis of nurses' working postures. Ergonomics 37(5): 909-919.

27. Kant J, Notermans J, Borm P (1990) Observations of working postures in garages using the OWAS-system and consequent workload reduction recommendations. Ergonomics 33(2): 209-220.

28. Gilkey DP, Keefe TJ, Bigelow PL, Herron RE, Duvall K (2007) Low Back Pain among Residential Carpenters: Ergonomic Evaluation Using OWAS and 2D Compression Estimation. Int J Occup Saf Ergon 13(3): 305-321.

29. Lee TH, Han CS (2013) Analysis of working postures at a construction site using the OWAS Method. Int J Occ Safety and Ergonomics 19(2): 245-250.

30. Rohmert W (1986) Ergonomics: concept of work, stress and strain. Appl Psychology 35(2): 159-180.

31. Kee D, Karwowski W (2007) A comparison of three observational techniques for assessing postural loads in industry. Int J Occ Safety and Ergonomics 13(1): 314.

32. Walker GH, Gibson H, Stanton NA, Baber C, Salmon P, et al. (2006) Event analysis of systemic teamwork (EAST): A novel and integration of ergonomics methods to analyse C4i activity. Ergonomics 49(1213): 1345-1360.

33. Buchholz B, Paquet V, Punnett L, Lee D, Moir S (1996) PATH: A work sampling approach to ergonomic job analysis for construction and other non-repetitive work. Appl Ergonomics 27(3): 177-187.

34. (2017) Contemplas.

35. (2017) DMC-ORTIM.

36. Lienert GA, Raatz U (1998) Testaufbau und Testanalyse. Psychologie Verlags Union, Weinheim (Germany).

37. Landau K, Nadeau S, Salmanzadeh H, Ahmadi A (2018) Evaluation of the Ergonomic Activity Sampling (EAS) method. Ergonomics International Journal (in prep).

38. Nadeau S, Le Floch T, Morency F, Landau K (2017) Ergonomie du dégivrage aéronautique en nacelles ouvertes (Rapport de recherche). Montréal École de technologie supérieure.

39. Landau K, Nadeau S, Le Floch T, Morency F (2017) Ergonomic Time and Motion Studies of Aircraft Deicing work. J Ergonomics 7: 204. 